Int. J. Electrochem. Sci., 14 (2019) $8228-8242$

\title{
Corrosion Behavior of Anodized 7B50 Aluminum Alloy in Different Atmospheric Environments
}

\author{
Qiyue Zhao ${ }^{1}$, Jinbin Zhao ${ }^{2}$, Chuang Guo ${ }^{1}$, Haiyan Wang ${ }^{1}$, Yunhua Huang ${ }^{1, *}$, Xuequn Cheng ${ }^{1}$, \\ Xiaogang $\mathrm{Li}^{l}$ \\ ${ }^{1}$ Corrosion and Protection Center, University of Science and Technology Beijing, Beijing 100083, \\ China \\ ${ }^{2}$ Jiangsu Key Laboratory for Premium Steel Material, Technology Center of Nanjing Iron \& Steel Co., \\ LTD, Nanjing 211500, China \\ *E-mail: huangyh@mater.ustb.edu.cn
}

doi: $10.20964 / 2019.08 .96$

Received: 17 April 2019 / Accepted: 11 June 2019 / Published: 30 June 2019

The corrosion behavior and mechanism of 7B50 aluminum alloy anodized in sulfuric acid solution were studied through outdoor exposure tests in industry-marine and northern semirural atmospheric environments in Qingdao and Beijing, respectively, by means of morphological observation, weight-loss measurement, X-ray diffraction and electrochemical impendence spectroscopy (EIS). The results showed that the average corrosion rates of the anodized alloy decreased by $91.9 \%$ and $56.2 \%$ after oneyear exposure in the industry-marine and northern semirural atmospheric environments, respectively, compared to the naked alloy. Thus the anodic treatment weakened corrosion and the effect was much better in the harsh environment. The high concentration of chloride ions in Qingdao played an important role in the destruction of the oxide films and in inducing the pitting corrosion. Due to the pitting on the grain boundaries and the microgalvanic corrosion among the grain boundary precipitates, precipitatefree zone and the matrix, the intergranular corrosion initiated and propagated throughout the sample. The sulfide in both atmospheres had a remarkable impact on the corrosion of 7B50 Al alloy, which aggravating surface and intergranular corrosion. The aggravation in Qingdao was much more serious. After exposure in Qingdao and Beijing, the anodized film remained an effective hindrance for aggressive ions penetrating to the matrix, and the barrier ability of the alloy in Beijing was better due to the intact double-layer structure of the film as well as the atmosphere's low humidity and low chloride ion concentration. The rust layer formed on the naked alloy was loose and cracked, which could not effectively obstruct the matrix corrosion.

Keywords: 7B50 aluminum alloy, anodizing in sulfuric acid, atmosphere corrosion, pitting corrosion, intergranular corrosion

\section{FULL TEXT}


(C) 2019 The Authors. Published by ESG (www.electrochemsci.org). This article is an open access article distributed under the terms and conditions of the Creative Commons Attribution license (http://creativecommons.org/licenses/by/4.0/). 